\title{
PREVISÃO DA VELOCIDADE DO VENTO A CURTO PRAZO EM REGIÃO TROPICAL UTILIZANDO WAVELETS E INTELIGÊNCIA ARTIFICIAL
}

Pedro Junior Zucatelli ; Erick Giovani Sperandio Nascimento²; Alex Álisson Bandeira Santos$^{2}$; Davidson Martins Moreira ${ }^{2}$

${ }^{1}$ Federal University of Espírito Santo, Av. Fernando Ferrari, 514, Goiabeiras, 29075910; Vitória/Espírito Santo; pedrojrzucatelli@gmail.com

${ }^{2}$ Manufacturing and Technology Integrated Campus SENAI CIMATEC, Av. Orlando Gomes, 1845, Piatã, 41650-010; Salvador/Bahia

Resumo: Neste trabalho, é apresentado a previsão da velocidade do vento a curto prazo na região tropical de Mucuri, Bahia, Brasil, aplicando algoritmo de aprendizado de máquina supervisionado por meio da Rede Neural Multilayer Perceptron, Rede Neural Recorrente e Decomposição Wavelet, isto para a série temporal horária representativa deste local. Para treinar a Rede Neural Artificial (RNA) e validar a técnica, dados anemométricos de um mês foram coletados por uma torre anemométrica com altura de $100 \mathrm{~m}$. Diferentes famílias de Wavelets e diferentes configurações de RNA foram aplicadas para este local e altura. Com base nos resultados alcançados, pode-se concluir que o método proposto (RNN + Meyer Wavelets) apresentou os melhores resultados no horizonte de previsão de curto prazo, isto é, $12 \mathrm{~h}$ à frente.

Palavras-Chave: Ciência Atmosférica; Ciência Computacional; Energia.

\section{SHORT-TERM WIND SPEED FORECASTING IN TROPICAL REGION USING WAVELETS AND ARTIFICIAL INTELLIGENCE}

\begin{abstract}
In this paper, the short-term wind speed forecasting in the tropical region of Mucuri, Bahia, Brazil, applying supervised machine learning algorithm by Multilayer Perceptron Neural Network, Recurrent Neural Network technique and Wavelet Packet Decomposition to the hourly time series representative of the site is presented. To train the Artificial Neural Network (ANN) and validate the technique, data for one month were collected by an anemometric tower at height of $100.0 \mathrm{~m}$. Different Wavelet families and different ANN configurations were applied for this site and height. Based on the outcomes of the study cases and results, it can be concluded that the proposed method (RNN + Meyer Wavelets) performed the best results in short-term forecasting horizon (12 $\mathrm{h}$ ahead).
\end{abstract}

Keywords: Atmospheric Science; Computer Science; Energy. 


\section{INTRODUCTION}

The reduction of emissions of greenhouse gases into the atmosphere has led many countries to increasingly seek the development of alternative sources of energy generation, including solar and wind energy, as well as the implementation of policies for sustainable energy sources [1]. In wind energy terms, it is known that the variability of wind direction and speed throughout the day makes it difficult to decide whether or not to drive wind turbines, because in practice, it is verified that the wind resource presents temporal variations in several orders of magnitude. The use of computational models can help both the identification of locations with high wind potential and, when used operationally in daily integrations, in the short-term energy generation forecast [2]. References [3], [4] and [5] showed results of mathematical modeling and numerical simulation for short-term wind speed predictions with computational intelligence techniques, especially using Multilayer Perceptron (MLP) and Recurrent Neural Networks (RNN) with Feedforward and Backpropagation training algorithm, all with good results achieved and low associated errors.

According to the literature [6], the Empirical Wavelet Transform (EWT) can effectively identify and extract a finite number of intrinsic modes of a wind speed time series. The use of wind power generation is very challenging for current power system operations. One reason for this is that wind power is an intermittent energy, which has strong randomness and instability [7]. Another reason is that wind power is a nondispatchable energy source, which cannot be controlled by operators in the same way as other electric power sources [8]. These problems can effectively be resolved if wind speed can be predicted accurately [9]. Therefore, improving the accuracy of short-term wind speed forecasting and developing new studies on this, are crucial for the operation of wind power plants, as in [10], [11], [12] and [13]. Furthermore, it is possible to cite recent studies of short-term wind speed forecasting, for example: [14], [15] and [5]. In all studies, when increasing the forecast interval there is an increase in the associated error of the forecasting.

In this context, this paper aimed to define the most efficient Wavelet Family, MLP and RNN configuration with Levenberg-Marquardt Backpropagation training algorithm, to predict the wind speed for 1 hour, and then infer the forecasting for 3,6 , 9 and 12 hours ahead, using as reference observational data collected from a anemometric tower installed at $100.0 \mathrm{~m}$, located in the tropical region of the Mucuri city, Bahia state, Brazil northeast, for the period between November 30, 2015 until December 31,2015 . The reason for choosing this period is due to be a dry season, where the water contribution for electric energy generation is compromised, being necessary the participation of alternative sources to complement the energy demand. This study is a novel investigation related to the operation of wind power plants for Mucuri. The main contributions of this study are provided as follows: a) The innovative aspect of this work is that it uses an approach to train the model for the next hour forecasting, then recursively inferring the forecasting for the following hours, in addition to applying this artificial intelligence method targeting short-range wind speed forecasting for this height in a tropical region. b) No previous studies applied computational intelligence for short-range wind speed forecasting for this height in such a humid tropical climate region (or humid coastal region). Therefore, the results constitute a significant contribution to the scientific community. c) The short-range wind 
speed forecasting model is an important contribution for reliable large-scale wind power forecasting and integration in Brazil. To reach the objective of the present work, the paper is organized as follows: section 2 presents the methodology adopted in the paper, section 3 is the numerical results and discussions, and finally, section 4 presents the conclusions.

\section{METHODOLOGY}

With respect to the computational procedure to perform this work, was adopted the computational intelligence model using Wavelets Packet Decomposition, Multilayer Perceptron, that is a class of feedforward artificial neural network, and Recurrent Neural Network with Levenberg-Marquardt Backpropagation training algorithm for short-range wind speed forecasting at Mucuri. According to [16], this type of neural network is the most usual for studies of this nature. Reference [17] describes that the aforementioned algorithm is the main neural network training algorithm. It is known that ANN are implemented through layers with interconnected nodes, also called neurons, and the definition of the number of layers is very variable, depending on the characteristics of each problem. They require at least three layers, being an input layer, a hidden layer and an output layer [18]. As all ANN needs to be trained, validated and tested, [19] describes that network training occurs in two phases in which each phase runs through the network in one direction. These two phases are called forward and backward. The forward phase defines the network output for a given input pattern. The backward phase uses the desired output and the output provided by the network to update the weights of its connections.

There are different possibilities for structuring an ANN, since it is necessary to select the type of neuron, the number of input parameters, the number of hidden layers, the type of training, and testing different configurations are usually employed for architecture, according to [20]. To develop an ANN model it is necessary to have a set of input parameters and an output set. These sets will be subdivided for use in two different steps: network training and validation of the produced estimates. The correct selection of the predictors is fundamental for a good performance of the model [21].

The Mucuri city is located at an altitude of $7.0 \mathrm{~m}$ in relation to the sea level and it has a territorial area of $1,775 \mathrm{~km}^{2}$, approximately. The Mucuri's anemometer tower is located in a coastal plain, at a distance of $340.0 \mathrm{~m}$ from the sea, with latitude $18^{\circ} 1^{\prime} 31.52 " \mathrm{~S}$ and longitude $39^{\circ} 30^{\prime} 51.69^{\prime \prime} \mathrm{W}$. The software used to program and perform this computational procedure was MATLAB version 7.10.0 2010, together with the NNTool (Neural Network Toolbox) graphical interface and Wavelet Analyzer. It is possible to observe, in Table 1, the information of each MLP and RNN configuration analyzed in this paper. The number of input nodes depends on the architecture being analyzed. In architecture 1 (Arch. 1), the input nodes are day, month, year, hour, wind speed ( $\mathrm{x}$-axis and $\mathrm{y}$-axis component), air temperature, air humidity and air pressure; in architecture 2 (Arch. 2), the value depends on the Wavelet level applied to wind speed decomposition. 
Table 1. MLP and RNN configurations.

\begin{tabular}{|c|c|c|c|c|c|}
\hline \multirow[b]{2}{*}{$\begin{array}{l}\text { MLP and RNN } \\
\text { config. and } \\
\text { Layer }\end{array}$} & Arch. 1 & Arch. 2 & \multirow[b]{2}{*}{$\begin{array}{l}1^{\text {st }} \text { hidden } \\
\text { layer }\end{array}$} & \multirow[b]{2}{*}{$\begin{array}{l}2^{\text {nd }} \text { hidden } \\
\text { layer }\end{array}$} & \multirow[b]{2}{*}{$\begin{array}{l}\text { Output } \\
\text { node }\end{array}$} \\
\hline & $\begin{array}{l}\text { MLP and } \\
\text { RNN input } \\
\text { node }\end{array}$ & $\begin{array}{c}\text { RNN + } \\
\text { Wavelets } \\
\text { input node }\end{array}$ & & & \\
\hline Config. I & 9 & $8 ; 10$ or 12 & 9 Neurons & - & 1 \\
\hline Config. II & 9 & $8 ; 10$ or 12 & 6 Neurons & - & 1 \\
\hline Config. III & 9 & $8 ; 10$ or 12 & 3 Neurons & - & 1 \\
\hline Config. IV & 9 & $8 ; 10$ or 12 & 1 Neuron & - & 1 \\
\hline Config. V & 9 & $8 ; 10$ or 12 & 9 Neurons & 6 Neurons & 1 \\
\hline Config. VI & 9 & $8 ; 10$ or 12 & 6 Neurons & 3 Neurons & 1 \\
\hline Config. VII & 9 & $8 ; 10$ or 12 & 1 Neuron & 1 Neuron & 1 \\
\hline
\end{tabular}

Each ANN presented in Table 1, from configurations I to VII, was trained (using Levenberg-Marquardt Backpropagation training algorithm), validated and tested to determine which would be the most efficient to perform short-term (1, 3, 6, 9 and 12 hours) wind speed forecasting. The activation functions that define the outputs of the neurons in terms of their activity levels, inserted in this simulation, were the sigmoidal function in the form of the hyperbolic tangent function (characterized as continuous, increasing, differentiable and non-linear) for hidden layers and linear function to the output layer. The Figure 1 shows the time series used in the models which consists of 744 data in total, corresponding to hourly mean data for each of the period November 30, 2015, 2:00 p.m. to December 31, 2015, 1:00 p.m.. The training set with 550 data was used for the models' training and validation. The prediction set consisting of 194 data was used to verify their accuracy during the prediction stage. As one can observe in this figure, there is noticeable data randomness and it is difficult to find a series tendency or seasonality.

Figure 1. Original wind speed time series.

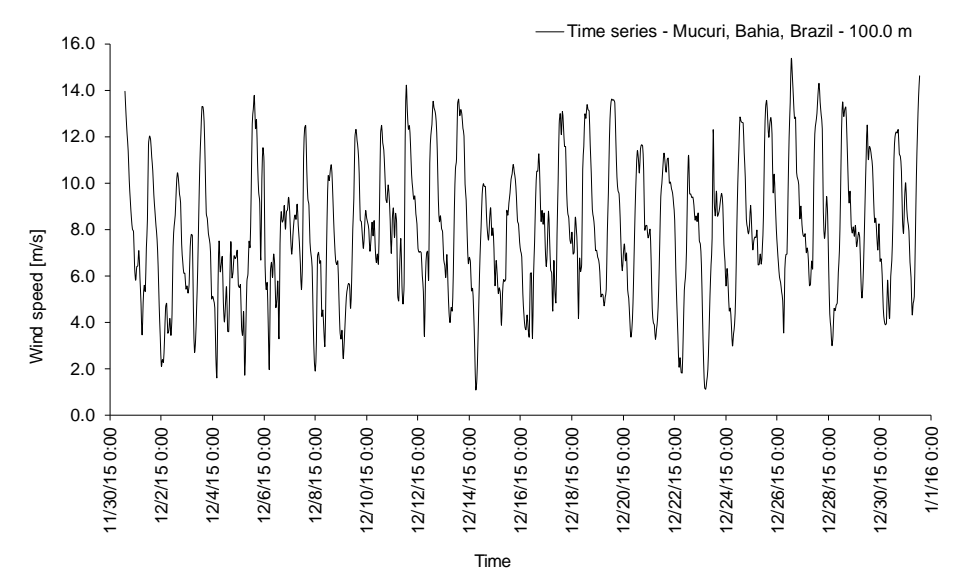

In this work the neural network was trained to perform the forecasting of 1 hour ahead and then, using it, the trained network was applied to recursively infer the forecasting for the next hours of the wind speed. The computational cost of this methodology, as applied in [5], is smaller than if it were necessary to train to predict the next $12 \mathrm{~h}$ for each input/sample of anemometric data. Therefore, to perform the prediction, the first phase is to identify what ANN (MLP and RNN) architecture can better perform the one hour forecasting of the wind speed for each height. Afterward, 
this predicted wind speed value is assigned as input for the second hour forecasting. So, it is calculated the forecast of the wind speed for the second hour. This procedure, highlighted in Figure 2, is repeated until the $n^{\text {th }}$ hour of the forecasting is reached. In this schema, the final result of the wind speed forecasting (ws) is: $w s=\sqrt{u^{2}+v^{2}}$. Next, the same schematic idea is used with the insertion of Wavelet decompositions. Figure 3 is the schematic example of the procedure used to compute the wind speed forecasting for 1, 3, 6, 9 and 12 hours ahead forward from start time using RNN + Wavelet decomposition. In this idea, the final result of the wind speed forecasting is the sum of the predicted detail and approximation components.

Figure 2. Schematic of the procedure used to compute the wind speed forecasting for 1,3 ,

6, 9 and 12 hours ahead forward from start time using artificial intelligence (MLP or

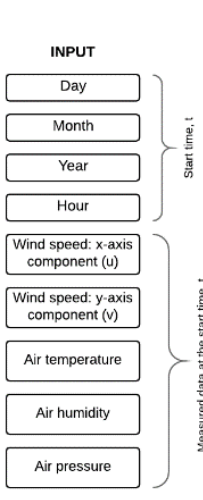
RNN).

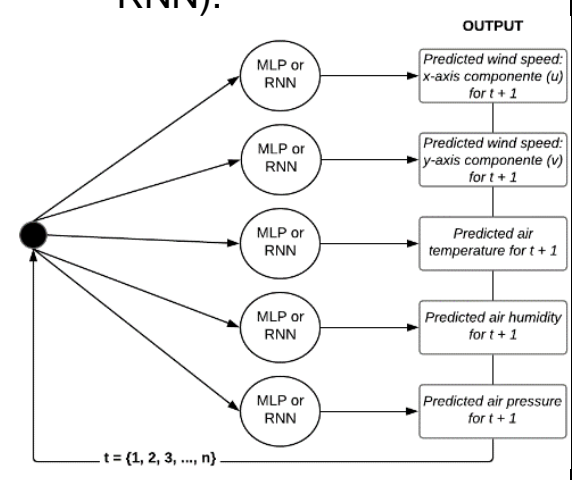

Figure 3. Schematic of the procedure used to compute the wind speed forecasting for $1,3,6,9$ and 12 hours ahead forward from start time using RNN + Wavelet.
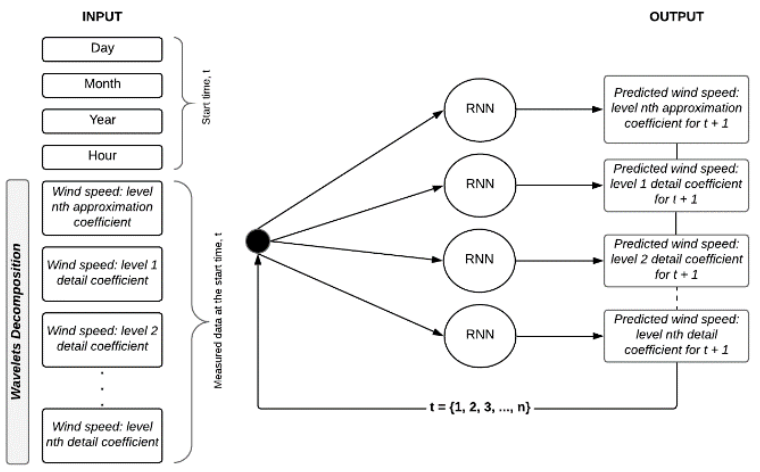

The Wavelet families applied to wind speed data decomposition were: Biorthogonal 3.9 level 3, Coiflet 5 level 3, Daubechies 7 level 3, Daubechies 8 level 5, Daubechies 9 level 7, Meyer level 3 and Symlet 7 level 3. In recent research, hybrid prediction models in wind power and wind speed forecasting have been proposed and investigated, which mainly contain the data preprocessing and forecast modeling [22]. The main technologies for these two modeling types are the signal decomposition algorithms and the prediction algorithms [23]. Thus, as the forecast time increases, it is expected that the quality of the predicted wind speed degrades by a certain degree, which will be evaluated in the next section: results and discussions.

\section{RESULTS AND DISCUSSIONS}

The statistical treatment employed in the results are Mean Absolute Error (MAE), Mean Squared Error (MSE), Root Mean Squared Error (RMSE), Mean Absolute Percentage Error (MAPE), $\mathrm{R}^{2}$ coefficient of determination, Pearson's correlation coefficient $(r)$ and percentage of data of factor of two. For these statistical indicators values close to 0.0 (zero) are adequate for the MAE, MSE, RMSE, MAPE errors, and values close to 1.0 (one) are adequate for the $\mathrm{R}^{2}$ and $r$ coefficients. Table 2 is a table comparison of the MSE and $R^{2}$ to MLP, RNN, and RNN + Wavelet. It shows that the RNN + Meyer Wavelet decomposition has the best result, as can be verified $\mathrm{MSE}=2.89$ and $\mathrm{R}^{2}=0.70$. 
Table 2. Table comparison of the MSE and $\mathrm{R}^{2}$ to $M L P, R N N$, and RNN + Wavelet.

\begin{tabular}{|l|c|c|c|}
\hline \multicolumn{1}{|c|}{ Model } & Time horizon & MSE & $\mathbf{R}^{\mathbf{2}}$ \\
\hline MLP & & 10.56 & 0.02 \\
\hline RNN & & 7.37 & 0.33 \\
\hline RNN + Biorthogonal Wavelets & & 5.43 & 0.58 \\
\hline RNN + Coiflet Wavelets & \multirow{4}{*}{12 h ahead } & 3.96 & 0.59 \\
\hline RNN + Meyer Wavelets & $\mathbf{2 . 8 9}$ & $\mathbf{0 . 7 0}$ \\
\hline RNN + Symlet Wavelets & 7.18 & 0.36 \\
\hline RNN + Daubechies 7 Wavelets & & 4.93 & 0.56 \\
\hline RNN + Daubechies 8 Wavelets & & 3.97 & 0.67 \\
\hline RNN + Daubechies 9 Wavelets & & 4.47 & 0.58 \\
\hline
\end{tabular}

Table 3 shows the evaluation metrics of the prediction results obtained by the best proposed model, RNN + Meyer Wavelet. The percentage of the data of a factor of two for wind speed forecasting $12 \mathrm{~h}$ ahead is $98.90 \%$. Figure 4 illustrate the shortrange wind speed forecasting and the factor of two to RNN + Meyer Wavelet.

Table 3. Statistical results (Errors and Regression): RNN + Meyer Wavelet.

\begin{tabular}{|c|c|c|c|c|c|c|c|}
\hline $\begin{array}{c}\text { Prediction } \\
\text { horizon }\end{array}$ & MAE & MSE & RMSE & MAPE & Pearson & $\mathbf{R}^{2}$ & $\begin{array}{c}\text { Percentage of the data } \\
\text { of a factor of two }\end{array}$ \\
\hline $1 \mathrm{~h}$ & 0.67 & 0.73 & 0.85 & $8.79 \%$ & 0.95 & 0.91 & $100.0 \%$ \\
\hline $3 \mathrm{~h}$ & 1.32 & 2.57 & 1.60 & $17.06 \%$ & 0.85 & 0.73 & $97.38 \%$ \\
\hline $6 \mathrm{~h}$ & 1.45 & 3.24 & 1.80 & $18.77 \%$ & 0.81 & 0.66 & $95.74 \%$ \\
\hline $9 \mathrm{~h}$ & 1.38 & 2.85 & 1.69 & $17.73 \%$ & 0.83 & 0.70 & $98.38 \%$ \\
\hline $12 \mathrm{~h}$ & 1.37 & 2.89 & 1.70 & $17.30 \%$ & 0.83 & 0.70 & $98.90 \%$ \\
\hline
\end{tabular}

Figure 4. Wind speed forecasting at $12 \mathrm{~h}$ ahead (RNN + Meyer Wavelet): a) The results of twelve-step predictions of the wind speed series. b) Comparison data of a factor of two (wind predicted/wind anemometer versus time) of the results obtained with the forecast model (twelve-step predictions) and the real data. c) Comparison data of a factor of two (wind predicted/wind anemometer versus wind anemometer) of the results obtained with the forecast model (twelve-step predictions) and the real data.

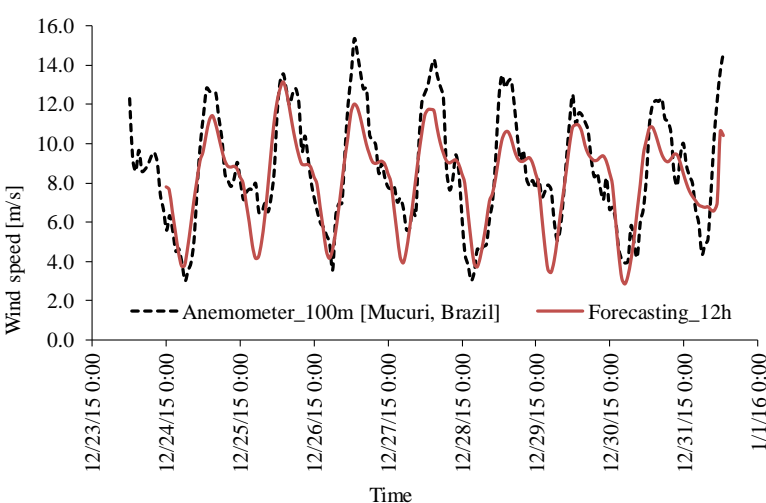

a)

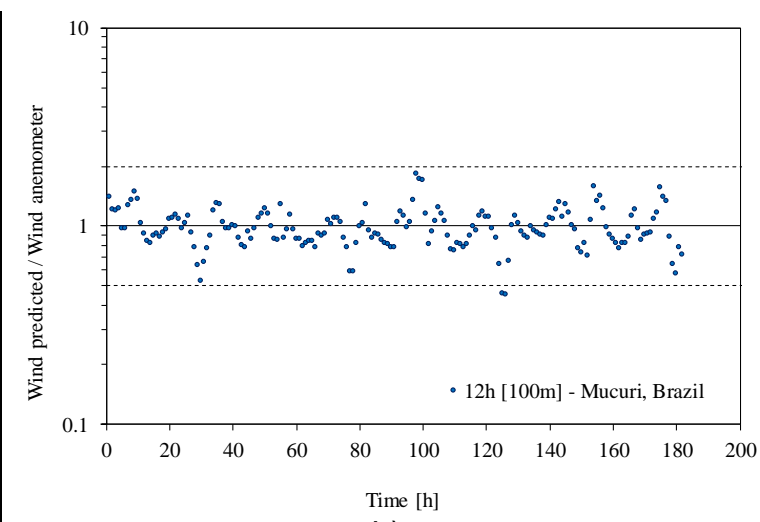

b) 


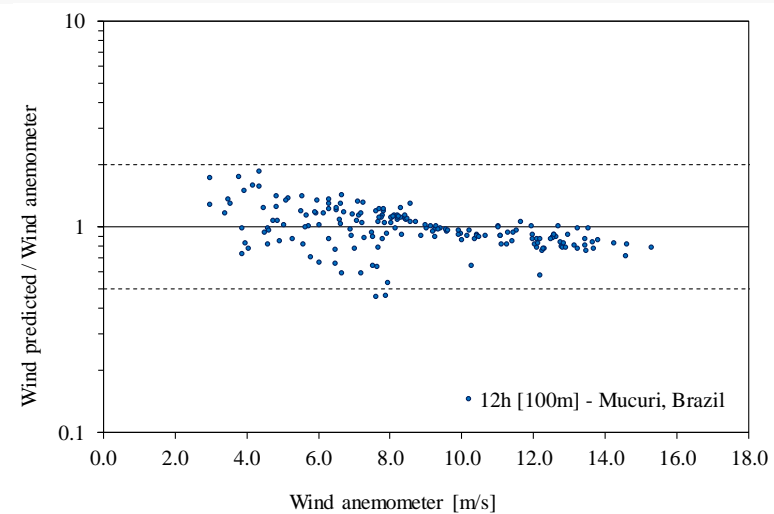

C)

These results are important to continue research on the role of the Wavelets transforms in the decomposition of the time series of the wind speed for later wind power forecasting. It should be emphasized that the computational cost of using computational intelligence in studies such as those carried out in this work increases as the expected workload increases, but it is still lower when compared to the cost of mathematical modeling and numerical simulation for prediction of wind speed using atmospheric models such as Weather Research and Forecasting (WRF). This is because in the WRF are implemented and solved the equations of transport phenomena and fluid mechanics, such as the Euler equations for compressible and non-hydrostatic fluid, in the form of fluxes, using conservative variables [24]. The proposed model can be used to identify optimal locations of wind turbines and forecast irregular wind energy, for different heights. Short-term wind energy forecasting can be improved using this model to enhance the wind power quality $12 \mathrm{~h}$ ahead.

\section{CONCLUSION}

In the light of the statistical results recorded in this work, the application of computational intelligence is a viable alternative for the predictability of wind speed and, in this way, wind power generation, mainly due to the low computational cost, however one must choose the RNN + Wavelet decomposition architecture that best suits the project, as well as quantitatively and qualitatively analyzes the available data that will feed the network, since these variables directly impact the results of the forecast. These results are presented as a novelty, since other works that used this computational model to predict wind speed for 1, 3, 6, 9 and 12 hours ahead in Brazil, especially in the Bahia state, were not found in the literature, particularly for very high positions of the anemometers, where wind turbines are usually positioned. Especially, it can be pointed out that the study presented good results, and, as the forecast time increases, the produced results not degrade, as expected, making it possible to use this technique to produce satisfactory forecasts of wind speed for short-term applications (till 12 hours ahead) with low computational costs, in order to help wind farm operators in decision-making processes. It is suggested as future work compare these results with the output produced by meteorological modelling (WRF model).

\section{ACKNOWLEDGMENT}

We thank FIEB and SENAI CIMATEC for their computational support. 


\section{REFERENCES}

1 CHENG, W.Y.Y., Liu, Y., Bourgeois, A.J., Wu, Y. and Haupt, S.E., 2017. Short-term wind forecast of a data assimilation/weather forecasting system with wind turbine anemometer measurement assimilation. Renewable Energy 107, 340-351.

2 PENG, H., Liu, F. and Yang, X., 2013. A hybrid strategy of short-term wind power prediction. Renewable Energy 50, 590-595.

3 WASILEWSKIA, J. and Baczynski, D., 2017. Short-term electric energy production forecasting at wind power plants in pareto-optimality context. Renewable and Sustainable Energy Reviews 69, 177187.

4 LIU, H., Mi, X., Li, Y., 2018. Wind speed forecasting method based on deep learning strategy using empirical wavelet transform, long short-term memory neural network and Elman neural network. Hui Liu; Xi-wei Mi; Yan-fei Li. Energy Conversion and Management. Volume 156, 15 January 2018, Pages 498-514. 2018.

5 ZUCATELLI, P.J., Nascimento, E.G.S., Aylas, G.Y.R., Souza, N.B.P., Kitagawa, Y.K.L., Santos, A.A.B., Arce, A.M.G., Moreira, D.M., 2019. Short-term wind speed forecasting in Uruguay using computational intelligence. Heliyon, Volume 5, Issue 5, May 2019, e01664.

$6 \mathrm{HU}$, J., Wang, J., Xiao, L., 2017. A hybrid approach based on the Gaussian process with tobservation model for short-term wind speed forecasts. Renew Energy 2017; 114:670-85.

7 ZHANG, J., Wei, Y., Tan, Z., Wang, K., and Tian, W., 2017. A Hybrid Method for Short-TermWind Speed Forecasting. Sustainability 9, 596.

8 ERDEM, E. and Shi, J., 2011. ARMA based approaches for forecasting the tuple of wind speed and direction. Appl. Energy 88, 1405-1414.

9 LIU, H.P., Shi, J. and Erdem, E., 2010. Prediction of wind speed time series using modified Taylor Kriging method. Energy 35, 4870-4879.

$10 \mathrm{LI}, \mathrm{G}$., Shi, J. and Zhou J., 2011. Bayesian adaptive combination of short-term wind speed forecasts from neural network models. Renew Energy, 36, $352-9$.

11 AKINCI, T.C., 2011. Short term wind speed forecasting with ANN in Batman, Turkey. Electron Electr Eng 1(107), 41-5.

12 NOGAY, H.S., Akinci, T.C. and Eidukeviciute, M., 2012. Application of artificial neural networks for short term wind speed forecasting in Mardin, Turkey. J. energy South. Afr. 23(4), 2-7.

13 OKUMUS, I. and Dinler, S., 2016. Current status of wind energy forecasting and a hybrid method for hourly predictions. Energy Conversion and Management 123, 362-371.

14 LIU, D., Wang, J. and Wang, H. 2015. Short-term wind speed forecasting based on spectral clustering and optimized echo state networks. Renew Energy 78, 599-608.

15 HU, Q., Zhang, R. and Zhou, Y., 2016. Transfer learning for short-term wind speed prediction with deep neural networks. Renew Energy 85, 83-95.

16 QIN, S., Liu, F., Wang, J. and Song, Y., 2015. Interval forecasts of a novelty hybrid model for wind speeds. Energy 1, 8-16.

17 CERVONE, G., Clemente-Harding, L., Alessandrini, S. and Monache, L.D., 2017. Short-term photovoltaic power forecasting using Artificial Neural Networks and an Analog Ensemble. Renewable Energy 108, 274-286.

18 RUSSEL, S. and Norvig, P., 2010. Artificial Intelligence: A Modern Approach. Stuart J. Russell and Peter Norvig. Third Edition. Pearson Education, Inc., 1153p.

19 PELLETIER, F., Masson, C. and Tahan, A., 2016. Wind turbine power curve modelling using artificial neural network. Renewable Energy 89, 207-214.

20 HAYKIN, S., 1999. Neural Networks: A Comprehensive Foundation. Simon Haykin. Second Edition. Pearson Education Inc. Hamilton, Ontario, Canada, 823p.

21 MORI, H. and Umezawa, Y., 2009. Application of NBTree to Selection of Meteorological Variables in Wind Speed Prediction, transmission \& Distribution Conference \& Exposition: Asia and Pacific, Seoul, Korea, 2009.

22 SUN S, Qiao H, Wei Y, Wang S., 2017. A new dynamic integrated approach for wind speed forecasting. Appl Energy 2017;197(June):151-62.

23 TASCIKARAOGLU A, Uzunoglu M., 2014. A review of combined approaches for prediction of shortterm wind speed and power. Renew Sustain Energy Rev 2014; 34:243-54.

24 SKAMAROCK, W.C., Klemp, J.B., Dudhia, J., Gill, D.O., Barker, D.M., Huang, X.Y., Wang, W. and Powers, J.G., 2008. A Description of the Advanced Research WRF Version 3 (NCAR Technical Note), Mesoscale and Microscale Meteorology Division do NCAR. Boulder, Colorado, USA. 